\title{
PENGARUH PROGRAM PELATIHAN FISIK MILITER TERHADAP PENINGKATAN VO2MAX SISWA PRA PENDIDIKAN DASAR RESIMEN MAHASISWA UNIVERSITAS NEGERI SEMARANG
}

\author{
Maula Hikam Pribany ${ }^{1}$, Sahri ${ }^{1}$
}

Jurusan Ilmu Keolahragaan, Fakultas Ilmu Keolahragaan, Universitas Negeri Semarang, Indonesia

\begin{abstract}
Info Artikel
Abstrak

Sejarah Artikel:

Program pelatihan fisik pra Pendidikan dasar Resimen Mahasiswa Universitas Negeri Semarang adalah program pelatihan fisik militer yang diadopsi dari TNI yang mana akan merubah jasmani

Diterima Februari 2021

Disetujui Juli 2021

Dipublikasikan Juli 2021 seorang, termasuk dalam kemampuan sistem alat gerak tubuh dan sistem kardiovaskulernya. Penelitian bertujuan untuk mengetahui apakah ada peningkatan kapasitas oksigen maksimal $\mathrm{VO}_{2}$ Max siswa pra pendidikan dasar Menwa UNNES dan seberapa besar peningkatan tersebut setelah menjalani pelatihan fisik militer selama 10 Minggu. Jenis penelitian adalah kuantitatif eksperimen menggunakan one group pre test and post test design. Populasi penelitian adalah semua siswa yang lolos seleksi. Sampel adalah 9 siswa putra dan 12 siswa putri yang bertahan hingga masa pra pendidikan dasar selesai. Pelatihan fisik militer antara lain lari pagi, sit up, push up, dan chinning

Kata Kunci: Bleep tes, Pelatihan fisik militer $\mathrm{VO}_{2} \mathrm{Max}$ Keywords:

Bleep test, Military physical training, $\mathrm{VO}_{2} \mathrm{Max}$ satu minggu dua kali yang dilaksanakan pada hari Rabu dan Sabtu. Bela diri resimen, PBB, PPM, dikperor, PUDD, keslap, senam senam senjata, teknik beregu, caraka, survival, pionering, IMPK, mountenering, nikpursar, pengjatri, dan HR yang dilaksanakan seminggu sekali pada hari Sabtu atau Minggu. VO2 maks diukur menggunakan bleep test yang dilakukan sebelum dan setelah pelaksanaan program pelatihan fisik militer. Hasil penelitian menunjukan VO2 maks meningkat dari (mean $\pm \mathrm{SD}$ ) $\mathrm{ml} / \mathrm{kg} /$ menit menjadi (mean $\pm \mathrm{SD}$ ) $\mathrm{ml} / \mathrm{kg} /$ menit dengan $\mathrm{t}$ (degress of freedomXX) $=\mathrm{XX}, \mathrm{p}<0,001$. Dapat disimpulkan bahwa latihan fisik pada program Pendidikan tersebut dapat meningkatkan VO2 maks siswa.
\end{abstract}

\begin{abstract}
Physical training program that is used in pre-primary training students of UNNES regiment is the military physical training program adopted from Indonesian National Armed Forces which would transform the physical body, including the ability of gestures system and cardiovascular system. The purpose is to determine whether there is an increase in the value of $V_{2}$ max of pre-primary training students of UNNES regiment and how much of enhancement after undergoing military for 10 weeks. Type of research is experimental quantitative research and uses pre-test and post-test design. The population were all students who passed the selection. The sample used was 9 male students and 12 female students who survived until the pre-primary education period was completed. Military physical training includes morning jogging, sit-ups, push-ups, and twice a week chinning held on Wednesday and Saturday. Regimental self-defense, line training, military tribute regulations, individual training, internal business regulations, field health, weapons gym, team work techniques, caraka, pioneering, battlefield and compass, mountaineering, basic combat techniques, weapons introduction, and obstacles are held once a week on Saturday or Sunday. The instrument was a bleep test conducted before and after the implementation of military physical training program. Based on the results of the study, it can be concluded that the value of Sig. (2-tailed) or p value from the paired sample t-test is 0,000. This means that $p$ value $<0.05$ which means there is a difference or significant increase between the results of the pre-test and post-test. The increase is from bad to good classification.
\end{abstract}

(C) 2021 Universitas Negeri Semarang

\footnotetext{
Alamat korespondensi:

Gedung F1 Lantai 1, IKOR FIK UNNES

Kampus Sekaran, Gunungpati, Kota Semarang, Indonesia, 50229

email: hikampribany@gmail.com
}

ISSN 2252-6528 


\section{PENDAHULUAN}

Anggota resimen mahasiswa adalah seorang mahasiswa yang dibekali ilmu olah keprajuritan di mana dalam hal fisik harus memiliki tingkat kebugaran jasmani yang lebih tinggi dibandingkan dengan mahasiswa biasa karena tugas dan tanggung jawab yang diemban di universitas berbeda dengan Unit Kegiatan Mahasiswa lainnya. Anggota Menwa dituntut memiliki daya tahan fisik dan kebugaran jasmani yang baik karena untuk melaksanakan tugas dari universitas tanpa mengalami dampak kelelahan yang berarti. Selain itu di luar tugas dari universitas, Menwa adalah sebuah komponen pasukan cadangan negara yang dipersiapkan sebagai pasukan cadangan pertahanan dan keamanan negara disaat negara mengalami kontak dengan negara lain.

Kebugaran jasmani dapat dipertahankan atau ditingkatkan dengan berbagai bentuk model pelatihan diiantaranya adalah dengan model pelatihan fisik militer. Pelatihan fisik militer memiliki tujuan untuk membentuk ketahanan fisik seorang prajurit sehingga mampu melakukan kegiatan dan pekerjaan yang berat. Salah satu unsur terpenting dalam kebugaran jasmani adalah daya tahan kardiorespirasi. Daya tahan kardiorespirasi adalah ketahanan organ jantung dan paru serta pembuluh darah mengambil oksigen kemudian mendistribusikannya ke sistem jaringan tubuh lain dalam proses metabolisme tubuh untuk melaksanakan fungsinya secara optimal dalam keadaan latihan dengan intensitas tinggi dan durasi waktu yang cukup lama.

Berdasarkan penggunaan oksigen dalam proses metabolismenya, latihan fisik dibagi menjadi dua, yaitu latihan aerobik dan anaerobik. Latihan aerobik adalah latihan yang menggunakan energi di mana dalam proses metabolismenya berasal dari pembakaran oksigen, seperti lari, jalan, bersepeda, treadmil dan renang. Olahraga aerobik dapat membuat kebugaran kardiorespirasi menjadi lebih baik karena olahraga tersebut mampu meningkatkan ambilan oksigen, meningkatkan kapasitas darah untuk mengangkut oksigen dan denyut nadi menjadi lebih rendah saat istirahat maupun aktivitas dan juga efektif dalam pengurangan masa lemak tubuh karena dalam aktifitas ini di saat metabolisme berjalan di dalam tubuh energi yang di gunakan yaitu berasal dari pembakaran glukosa dan lemak.

Salah satu cara menilai kebugaran dalam melakukan aktivitas fisik adalah mengukur volume oksigen maksimal dalam tubuh $\left(\mathrm{VO}_{2} \mathrm{Max}\right)$. VO2Max adalah kemampuan seseorang mempergunakan sistem jantung dan paru-paru serta peredaran darahnya dalam beraktivitas dalam waktu yang relatif lama dan dihitung dengan perbandingan berat badan per menit. Menurut Guyton dan Hall (2008) dalam Giri Wiarto (2013:13), $\mathrm{VO}_{2} \mathrm{Max}$ adalah kecepatan pemakaian oksigen dalam metabolisme aerob maksimum. Sedangkan menurut Thoden dalam modul Suranto (2008:118), $\mathrm{VO}_{2} \mathrm{Max}$ merupakan daya tangkap aerobik maksimal menggambarkan jumlah oksigen maksimum yang dikonsumsi per satuan waktu oleh seseorang selama latihan atau tes, dengan latihan yang makin lama makin berat sampai merasakan kelelahan fisik. Besarnya $V_{2} \mathrm{Max}$ seseorang tergantung pada kekuatan sistem kardiovaskuler. Kekuatan sistem kardiovaskuler seseorang bergantung pada aktivitas fisik sehari-hari dan program pelatihan yang dijalankan. Karena $\mathrm{VO}_{2} \mathrm{Max}$ adalah volume oksigen, ukurannya disebut $\mathrm{VO}_{2} \mathrm{Max}$. Semua selaras dengan pendapat dari Kusmana (2002:138), yang mendefinisikan bahwa kapasitas kerja maksimal aerobik $\left(\mathrm{VO}_{2} \mathrm{Max}\right)$ adalah jumlah terbesar oksigen yang dapat digunakan selama latihan fisik (di atas permukaan laut) dan 
mencerminkan kemampuan untuk mengirim oksigen ke jaringan tubuh per kilogram berat badan per menit. Orang yang memiliki kebugaran baik mempunyai nilai $\mathrm{VO}_{2} \mathrm{Max}$ yang lebih tinggi, sehingga dapat melakukan aktivitas lebih lama. $\mathrm{VO}_{2} \mathrm{Max}$ adalah faktor yang sangat penting bagi kebugaran fisik seseorang, terlebih bagi para anggota Menwa yang kesehariannya tidak pernah jauh dari aktivitas maksimum, maka pelatihan yang dibutuhkan adalah pelatihan yang bersifat aerobik (Caine, 1999:623).

Berdasarkan latar belakang di atas, maka perlu adanya penelitian untuk siswa Pra Pendidikan Dasar Keprajuritan Resimen Mahasiswa Universitas Negeri Semarang karena masa pra pendidikan dasar ini merupakan masa yang krusial, yaitu masa peralihan dari sipil (mahasiswa biasa) ke militer, baik secara fisik maupun mental yang khususnya untuk mempersiapkan anggota Menwa UNNES dalam Pendidikan Dasar Keprajuritan di Dodik bela negara Rindam IV/Diponegoro, Magelang. Sehingga, dari permasalahan $\mathrm{di}$ atas peneliti memiliki tujuan mengetahui model pelatihan yang selama ini diterapkan sudah sesuai dan memiliki progres dalam peningkatan VO2Max atau belum serta mengetahui berapa besar peningkatan tersebut.

\section{METODE}

Penelian ini merupakan penelitian kuantitatif menggunakan pre test and post test design. Sampel akan mendapatkan perlakuan berupa pelatihan fisik militer dalam masa pra Pendidikan dasar di mana sebelumnya akan dilaksanakan pre test dan setelah treatment dilaksanakan post test. Instrumen dalam penelitian ini menggunakan bleep test. Bleep test adalah sebuah tes yang sering digunakan untuk mengukur $\mathrm{VO}_{2} \mathrm{Max}$ seseorang melaluai hasil lari bolak-balik yang mengikuti bunyi irama bip dengan jarak tempuh 20 meter. Teknik pengumpulan data menggunakan belangko atau form nilai tes. Analisis data penelitian menggunakan aplikasi SPSS versi 25.0. Sebelum melakukan uji hipotesis, dilakukan uji prasarat terlebih dahulu yang meliputi uji normalitas dan uji homogenitas, setelah itu barulah melakukan uji hipotesis menggunakan uji Paired sample $T$ Test guna mengetahui hasil penelitian.

\section{HASIL DAN PEMBAHASAN}

Data penelitian ini berupa angka yang menunjukan hasil dari tes yang telah dilakukan saat penelitian. Hasil data yang didapatkan lalu diolah dengan membandingkan hasil tes yang sama yaitu bleep test, dari sebelum diberikan perlakuan dan setelah diberikan perlakuan. Bleep test ini dilaksanakan di awal pra Pendidikan dasar/ pre tes dan setelah pra Pendidikan dasar/ post tes dengan rentang waktu 10 minggu. Populasi pada penelitian ini adalah siswa Menwa pra pendidikan dasar kemiliteran yudha XLII Universitas Negeri Semarang. Sampel yang di gunakan adalah seluruh siswa yang bertahan sampai dengan masa pra Pendidikan selesai yaitu sejumlah 21 siswa yang terdiri dari 9 siswa putra dan 12 siswa putri.

\section{Analisis Deskripsi Pre Test}

Pre test dilakukan menggunakan instrumen bleep test. Tes ini menggunakan sampel berjumlah 21 siswa Menwa atau total keseluruhan siswa Menwa pra pendidikan dasar yang bertahan sampai dengan selesai. Hasil tes di catat dalam lembar penilaian bleep tes yang di tulis oleh sampel yang sedang tidak melakukan bleep test tersebut. Minimal nilai pre test sampel putra adalah 25,6 dan nilai maksimal adalah 44,2 dengan nilai rata-rata 36,8 . Minimal nilai pre test sampel putri adalah 22,8 dan nilai maksimal 
adalah 31,8 dengan nilai rata-rata 25,4.

Sedangkan nilai standar deviasinya adalah 7,39.

Berikut tabel 1.1 menjabarkan hasil analisis deskripsi terhadap data yang telah diperoleh dari pre test dan table 1.2 menjabarkan klasifikasi data hasil pre test

Tabel 1.1 Deskripsi Statistik Data Hasil Pre Test

\begin{tabular}{cccccc}
\hline Pre Tes & N & $\begin{array}{c}\text { Minim } \\
\text { um }\end{array}$ & $\begin{array}{c}\text { Maxim } \\
\text { um }\end{array}$ & $\begin{array}{c}\text { Mea } \\
\mathbf{n}\end{array}$ & $\begin{array}{c}\text { Std. } \\
\text { Deviatio } \\
\text { n }\end{array}$ \\
\hline Putra & 9 & 25,6 & 44,2 & 36,8 & 7,39195 \\
Putri & 12 & 22,8 & 31,8 & 25,4 & \\
N Total & 21 & & & & \\
\end{tabular}

Tabel 1.2 Klasifikasi Data Hasil Pre Test

\begin{tabular}{|c|c|c|c|c|c|c|}
\hline \multirow[t]{2}{*}{$\begin{array}{c}\text { Klasifik } \\
\text { asi }\end{array}$} & \multicolumn{2}{|c|}{ N Sampel } & \multicolumn{2}{|c|}{$\begin{array}{c}\text { Jumlah } \\
\text { Klasifikas } \\
\text { i }\end{array}$} & \multicolumn{2}{|c|}{ Prosentase } \\
\hline & $\begin{array}{c}\text { put } \\
\text { ra }\end{array}$ & $\begin{array}{c}\text { Put } \\
\text { ri }\end{array}$ & $\begin{array}{c}\text { put } \\
\text { ra }\end{array}$ & $\begin{array}{c}\text { Put } \\
\text { ri }\end{array}$ & putra & putri \\
\hline $\begin{array}{l}\text { Sangat } \\
\text { buruk }\end{array}$ & 9 & 12 & 3 & 8 & $\begin{array}{c}33,33 \\
\%\end{array}$ & $\begin{array}{c}66,67 \\
\%\end{array}$ \\
\hline Buruk & 9 & 12 & 2 & 3 & $\begin{array}{c}22,22 \\
\%\end{array}$ & $25 \%$ \\
\hline Normal & 9 & 12 & 4 & 1 & $\begin{array}{c}44,44 \\
\%\end{array}$ & $\begin{array}{c}8,33 \\
\%\end{array}$ \\
\hline Baik & 9 & 12 & 0 & 0 & $0 \%$ & $0 \%$ \\
\hline $\begin{array}{c}\text { Sangat } \\
\text { baik }\end{array}$ & 9 & 12 & 0 & 0 & $0 \%$ & $0 \%$ \\
\hline Superior & 9 & 12 & 0 & 0 & $0 \%$ & $0 \%$ \\
\hline
\end{tabular}

\section{Analisis Deskripsi Post Tes}

Post test dilakukan menggunakan instrument bleep test. Tes ini menggunakan sampel berjumlah 21 siswa Menwa atau total keseluruhan siswa Menwa pra pendidikan dasar. Hasil tes di catat dalam lembar penilaian bleep tes yang di tulis oleh sampel yang sedang tidak melakukan bleep tes tersebut. Berikut tabel 1.3 menjabarkan hasil analisis deskripsi terhadap data yang telah diperoleh dari post test dan tabel 1.4 menjabarkan klasifikasi data hasil post test:

Tabel 2.1 Deskripsi Statistik Data Hasil Post Test

\begin{tabular}{|c|c|c|c|c|}
\hline Pre Test & $\mathbf{N}$ & $\begin{array}{l}\text { Mini } \\
\text { mum }\end{array}$ & $\begin{array}{l}\text { Maxi } \\
\text { mum }\end{array}$ & Mean \\
\hline
\end{tabular}

$$
\begin{array}{cccccc}
\text { Putra } & 9 & 37,1 & 66,2 & 50,1 & 10,09883 \\
\text { Putri } & 12 & 30,2 & 49,0 & 36,4 & \\
\text { N } & 21 & & & & \\
\text { Total } & & & & &
\end{array}
$$

\begin{tabular}{|c|c|c|c|c|c|c|}
\hline \multirow[t]{2}{*}{$\begin{array}{l}\text { Klasifikas } \\
\text { i }\end{array}$} & \multicolumn{2}{|c|}{ N sampel } & \multicolumn{2}{|c|}{$\begin{array}{c}\text { jumlah } \\
\text { klasifikasi }\end{array}$} & \multicolumn{2}{|c|}{ prosentase } \\
\hline & putra & Putri & putra & putri & putra & putri \\
\hline $\begin{array}{l}\text { Sangat } \\
\text { buruk }\end{array}$ & 9 & 12 & 0 & 0 & $0 \%$ & $0 \%$ \\
\hline Buruk & 9 & 12 & 2 & 1 & $\begin{array}{c}22,22 \\
\%\end{array}$ & $8,33 \%$ \\
\hline Normal & 9 & 12 & 2 & 4 & $\begin{array}{c}22,22 \\
\%\end{array}$ & $\begin{array}{c}33,33 \\
\%\end{array}$ \\
\hline Baik & 9 & 12 & 1 & 4 & $\begin{array}{c}11,11 \\
\%\end{array}$ & $\begin{array}{c}33,33 \\
\%\end{array}$ \\
\hline $\begin{array}{c}\text { Sangat } \\
\text { baik }\end{array}$ & 9 & 12 & 1 & 1 & $\begin{array}{c}11,11 \\
\%\end{array}$ & $8,33 \%$ \\
\hline Superior & 9 & 12 & 3 & 2 & $\begin{array}{c}33,33 \\
\%\end{array}$ & $\begin{array}{c}16,67 \\
\%\end{array}$ \\
\hline
\end{tabular}

Tabel 2.2 Klasifikasi Data Hasil Post Test

\section{Uji Normalitas Data}

Penghitungan ini menggunakan program komputer SPSS versi 25.0. Kriteria yang digunakan untuk menentukan normalitasnya adalah jika nilai signifikansi $(S i g) \leq 0,05$, maka data berdistribusi tidak normal, dan jika nilai signifikansi $($ Sig $)>0,05$, maka data berdistribusi normal. Penghitungan uji normalitas dilakukan

\begin{tabular}{|c|c|c|c|}
\hline \multicolumn{4}{|c|}{ One-Sample Kolmogorov-Smirnov Test } \\
\hline \multicolumn{2}{|c|}{$\mathbf{N}$} & $\begin{array}{c}P R E T E \\
S T \\
21\end{array}$ & $\begin{array}{c}\text { POSTEST } \\
21\end{array}$ \\
\hline \multirow{2}{*}{$\begin{array}{c}\text { Normal } \\
\text { Parameters }^{a, b}\end{array}$} & Mean & 302.90 & 422.81 \\
\hline & $\begin{array}{c}\text { Std. } \\
\text { Deviati } \\
\text { on }\end{array}$ & 73.919 & 100.920 \\
\hline $\begin{array}{c}\text { Most } \\
\text { Extreme }\end{array}$ & $\begin{array}{c}\text { Absolu } \\
\text { te }\end{array}$ & .166 & .133 \\
\hline \multirow[t]{2}{*}{ Differences } & $\begin{array}{c}\text { Positiv } \\
e\end{array}$ & .166 & .133 \\
\hline & $\begin{array}{l}\text { Negati } \\
\text { ve }\end{array}$ & -.155 & -.116 \\
\hline \multicolumn{2}{|c|}{ Test Statistic } & .166 & .133 \\
\hline \multicolumn{2}{|c|}{ Asymp. Sig. (2-tailed) } & $.136^{\mathrm{c}}$ & $.200^{\mathrm{c}}$ \\
\hline
\end{tabular}
pada data dari masing-masing variabel, yaitu hasil pre test dan post test.

Tabel 3 Hasil Uji Normalitas 
Berdasarkan tabel 3. Output SPSS "OneSample Kolmogorov-Smirnov Test" diperoleh informasi nilai Asymp. Sig. (2-tailed) masingmasing variabel adalah sebagai berikut:

a. Variabel hasil pre test diperoleh 0,136

b. Variabel post test diperoleh 0,200

Karena nilai Asymp. Sig. (2-tailed) untuk ke-2 variabel di atas lebih dari 0,05, maka dapat disimpulkan bahwa data dari ke-2 variabel tersebut adalah berdisrtribusi normal.

\section{Uji Homogenitas Data}

\section{Paired Samples Test}

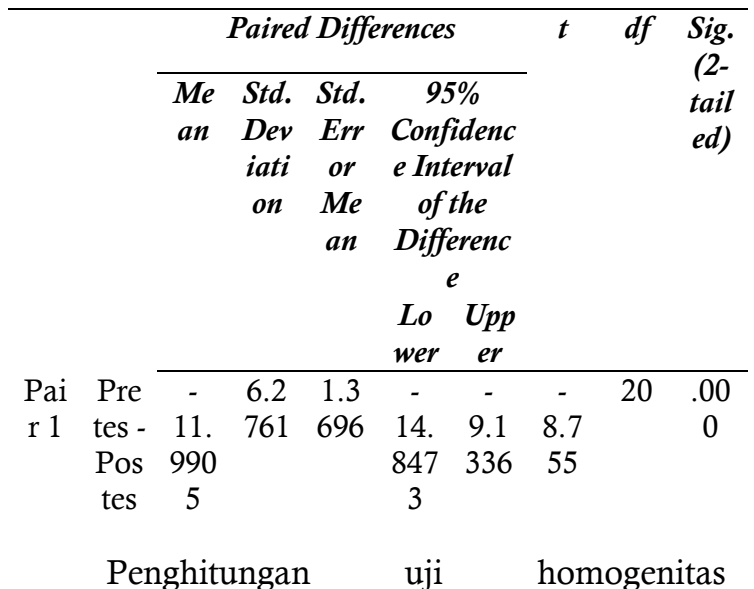

menggunakan program komputer SPSS versi 25.0. Kriteria untuk menentukan homogenitasnya adalah jika nilai signifikansi $(\operatorname{Sig}) \leq 0,05$, maka data tidak homogen dan jika nilai signifikansi $($ Sig) $>0,05$ maka data homogen. Penghitungan uji homogenitas dilakukan pada data dari masing-masing variabel, yaitu hasil pre test dan post test.

Tabel 4 Hasil Uji Homogenitas

\begin{tabular}{|c|c|c|c|c|c|}
\hline \multicolumn{6}{|c|}{ Test of Homogeneity of Variances } \\
\hline \multirow{4}{*}{$\begin{array}{c}\text { NIL } \\
\text { AI }\end{array}$} & & $\begin{array}{c}\text { Levene } \\
\text { Statist } \\
\text { ic }\end{array}$ & $d f 1$ & $d f 2$ & $\begin{array}{c}\text { Sig } \\
\text {. }\end{array}$ \\
\hline & $\begin{array}{c}\text { Based on } \\
\text { Mean }\end{array}$ & 1.851 & 1 & 40 & $\begin{array}{l}.1 \\
81\end{array}$ \\
\hline & $\begin{array}{l}\text { Based on } \\
\text { Median }\end{array}$ & 1.489 & 1 & 40 & $\begin{array}{l}.2 \\
29\end{array}$ \\
\hline & $\begin{array}{l}\text { Based on } \\
\text { Median } \\
\text { and with } \\
\text { adjusted }\end{array}$ & 1.489 & 1 & $\begin{array}{l}37 \\
.8 \\
44\end{array}$ & $\begin{array}{l}.2 \\
30\end{array}$ \\
\hline
\end{tabular}

\begin{tabular}{ccccc}
\hline$d f$ & & & & \\
Based on & 1.713 & 1 & 40 & .1 \\
trimmed & & & & 98 \\
mean & & & & \\
\hline
\end{tabular}

Berdasarkan tabel 4, yaitu hasil uji homogenitas diperoleh informasi bahwa nilai signifikansi 0,198. Nilai signifikansi adalah $0,198>0,05$. Sehingga, dapat disimpulkan pengujian ke-2 variabel mempunyai varian yang sama atau homogen.

\section{Uji Hipotesis}

Uji beda Paired Sample $T$ Test ini digunakan untuk melihat ada atau tidak perbedaan dan peningkatan antara hasil pre test dengan post test pada siswa pra Pendidikan dasar Menwa UNNES. Untuk melihat hasil dari uji Paired Sample T Test dalam aplikasi SPSS versi 25.0 yaitu sebagai berikut :

\section{Tabel 5 Hasil Uji Hipotesis}

\begin{tabular}{ccccc}
\hline \multicolumn{4}{c}{ Paired Samples Correlations } \\
\hline & & $\mathbf{N}$ & Correlation & Sig. \\
Pair & Pre Test \& & 2 & .785 & .000 \\
1 & Post Tes & 1 & & \\
\hline
\end{tabular}

Berdasarkan tabel 5 karena nilai t hitung negatif maka terdapat perbedaan bermakna apabila $\mathrm{t}$ hitung $<\mathrm{t}$ tabel. Melihat nilai Sig. (2tailed) atau $\mathrm{p}$ value. Pada kasus di atas nilai $\mathrm{p}$ value sebesar 0,000. Di mana $\mathrm{p}$ value $<0,05$ maka terdapat perbedaan bermakna secara statistik atau signifikan antara hasil pre test dan post test.

\section{Pembahasan}

Pelatihan fisik militer yang di terapkan dalam masa pra pendidikan dasar Menwa UNNES yaitu bersifat aerobik dan anaerobik yang dilaksanakan setiap satu minggu sekali selama 10 minggu. Terdapat beberapa hal yang akan dibahas dalam pembahasan penelitian ini. Hal yang menjadi aspek dalam menentukan hasil penelitian dan pembuktian hipotesis penelitian ini. Diantaranya adalah: 


\subsection{Aspek Fisiologi Olahraga}

Menjadi seorang anggota Menwa berbeda dengan menjadi anggota UKM lain di kampus. Karena tugas pokok dan fungsi seorang Menwa menuntut untuk selalu siap sedia jika di butuhkan universitas dan masyarakat sekitaer dalam kegiatan pengamanan maupun pengabdian dan kegiatan bakti sosial yang lain sehingga setiap anggota di tuntut untuk memiliki fisik yang kuat dan prima. Fisik kuat dan prima yang di maksudkan tidak hanya kuat dalam sistem alat gerak yaitu tulang dan otot namun juga kuat dalam sistem kardiovaskuler atau VO2Max.

Penentuan calon siswa Menwa harus memenuhi kriteria yang sudah di tentukan. Maka dari itu di adakan seleksi secara administrasi dan fisik di awal proses perekrutannya. Dalam menentukan jumlah sampel penelitian, selain didasari pada hasil seleksi namun juga didasari karena seberapa jauh siswa tersebut dapat bertahan. Maka dari itu jumlah siswa yang mengikuti pre test berbeda jumlahnya dengan yang mengikuti post test.

Pemberian pelatihan fisik militer yang di berikan membuat siswa pra Pendidikan dasar Menwa mengalami peningkatan kemampuan dalam sistem tubuh mereka. Baik peningkatan secara sistem alat gerak juga peningkatan dalam sistem kardiovaskuler. Hal ini di sebebkan karena dalam pelatihan fisik militer terdapat jenis latihan aerobik dan anaerobik.

\subsection{Aspek Hasil Tes}

Proses pengklasifikasian data hasil penelitian antara sampel putra dan sampel putri dibedakan. Hal itu dikarenakan norma dalam tabel penilaian antara putra dan putri berbeda. Berdasarkan hasil penelitian diperoleh pernyataan bahwa terdapat perbedaan antara hasil pre test dan post test setelah melakukan uji beda dengan menggunakan Paired sample $T$ Test, diperoleh signifikansi sebesar 0,000 yang artinya $\mathrm{p}<0,05$. Hal ini menunjukan bahwasannya hipotesis dalam penelitian ini sesuai dengan hasil dari penelitian. Pada penelitian ini mayoritas hasil yang diperoleh dari sampel mengalami peningkatan. Hasil pre test yang lebih kecil daripada hasil post test, artinya bahwa pelatihan fisik militer yang di laksanakan dalam masa pra pendidikan dasar ini memberikan hasil peningkatan VO2Max pada mayoritas sampel.

Jadi dapat disimpulkan bahwasanya dari hasil penilitian menunjukan ada peningkatan $\mathrm{VO}_{2} \mathrm{Max}$ Siswa Menwa Unnes setelah melaksanakan pelatihan fisik militer dalam Pra Pendidikan Dasar. Besarnya peningkatan $\mathrm{VO}_{2} \mathrm{Max}$ Siswa Menwa Unnes setelah melaksanakan pelatihan fisik militer dalam Pra Pendidikan Dasar yaitu 13,3 poin untuk siswa putra dari hasil rata-rata nilai pre test 36,8 dengan klasifikasi buruk dan hasil rata-rata nilai post test 50,1 dengan klasifikasi baik. Lalu 11 poin untuk besarnya peningkatan siswa putri dari hasil ratarata nilai pre test 25,4 dengan klasifikasi buruk dan hasil rata-rata nilai post test 36,4 dengan klasifikasi baik.

\section{SIMPULAN}

Berdasarkan hasil Penelitian dan pembahasan didapatkan kesimpulan, bahwa terdapat peningkatan VO2Max siswa Menwa UNNES setelah melaksanakan pelatihan fisik militer dalam masa pra pendidikan dasar.

\section{UCAPAN TERIMA KASIH}

Dalam kesempatan ini penulis menyampaikan ucapan terima kasih kepada seluruh jajaran dalam Jurusan Ilmu Keolahragaan Fakultas Ilmu Keolahragaan Universitas Negeri Semarang yang telah memberikan bimbingan dan waktunya sehingga saya mampu menyelesaikan 
penelitian ini, juga kepada sahabat dan temanteman, serta rekan UKM Resimen Mahasiswa Universitas Negeri Semarang yang telah memberikan bantuan berupa dukungan dan semangat untuk melaksanakan penelitian ini.

\section{DAFTAR PUSTAKA}

Afriwardi. 2009. Pengaruh Pemulihan Aktif dan Pemulihan Pasif Terhadap Lamanya Perubahan Kadar Laktat Darah.Jurnal Kedokteran Andalas. No.2.vol.32

Ancok, D Dkk. 2017. Modul Kesamaptaan . Jakarta : Lembaga Administrasi Negara

Arikunto, S. 2009. Prosedur Penelitian. Jakarta : PT Rineka Cipta

Bafirman,HB. 2013. Kontribusi Fisiologi Olahraga Mengatasi Resiko Menuju Prestasi Optimal. Jurnal Media Ilmu Keolahragaan Indonesia. Vol.3.edisi 1. ISSN: 2088-6802.

Hernawati.2012. Produksi Asam Laktat pada Exercise Aerobik dan Anaerobik. Bandung:UPI Press

Irawan,M. 2009. Nutrisi,Energi dan Performa Olahraga. Polton Sport Science Brief and Performance Lab. Vol. 01.no.04

Peraturan Kepala Basarnas Nomor: PK. 24 Tahun 2009 Tentang Petunjuk Pelaksanaan Pemeriksaan Kesemaptaan Jasmani dan Kesehatan Pada Seleksi Penerimaan Calon Pegawai Negeri Sipil di Lingkugan Badan SAR Nasional.

Sugiyono. 2006. Statistika Untuk Penelitian . Bandung : CV Alfabeta

Sujarweni, Wiratna. (2008). Belajar Mudah SPSS Untuk Penelitian Skripsi, Tesisi, Desertasi, dan Umum. Yogyakarta: Ardana Media.

Suryanti, E. 2009. Hubungan Tingkat Kesegaran Jasmani Terhadap Prestasi Belajar Pada Siswa Kelas V Putra SD Negeri Dabin Candra.Skripsi. UNNES 